movements (6), this infection was considered to be autochthonous, indicating endemicity of the $C$. gattii VGIIb-like variant in Nova Scotia and highlighting the value of nonmigratory animals as sentinels for emerging diseases (7). Incidence for this disease is highest in the Pacific Northwest, where the primary agents are $C$. gattii VGII genotypes $(2,4)$. A pertinent literature review and consultation with regional public and veterinary health authorities determined that Québec was the most eastern province in Canada where crytococcosis associated with $C$. gattii VGII has caused clinical disease that was not potentially travel related in humans (Phillippe Dufresne, pers. comm.). In eastern North America, the C. gattii VGIIb genotype is reported to have caused disseminated cryptococcosis in a human in Florida, USA $(8,9)$. Because $C$. gattii is potentially pervasive in the environment, the Nova Scotia Department of Health has alerted provincial infectious disease specialists and the provincial public health laboratory to ensure availability of the diagnostic capacity to test for the fungus.

The C. gattii VGIIb genotype causes substantial, lifethreatening disease in otherwise healthy hosts (2), and a unique VGIIb-like variant is endemic to Atlantic Canada. Therefore, continued surveillance by physicians and veterinarians in the region is warranted.

\section{Acknowledgments}

We thank Beatrice Despres for her technical support in the operation and maintenance of matrix-assisted laser desorption/ ionization time-of-flight mass spectrometry for sample analysis. We also thank Bob Petri and Donald Sam for their ongoing support of the scanning wildlife health surveillance program in Atlantic Canada and encouragement of Nova Scotia Department of Natural Resources field staff to take the time and make the effort to submit diagnostic specimens from the whitetailed deer, enabling a confirmatory diagnosis for this index case of cryptococcosis in Atlantic Canada.

The cost of the diagnostic testing for this case was covered by the scanning wildlife health surveillance program of the Canadian Wildlife Health Cooperative.

\section{References}

1. Lester SJ, Malik R, Bartlett KH, Duncan CG. Cryptococcosis: update and emergence of Cryptococcus gattii. Vet Clin Pathol. 2011;40:4-17. http://dx.doi.org/10.1111/j.1939-165X.2010.00281.x

2. Espinel-Ingroff A, Kidd SE. Current trends in the prevalence of Cryptococcus gattii in the United States and Canada. Infect Drug Resist. 2015;8:89-97. http://dx.doi.org/10.2147/IDR.S57686

3. Meyer W, Aanensen DM, Boekhout T, Cogliati M, Diaz MR, Esposto $\mathrm{MC}$, et al. Consensus multi-locus sequence typing scheme for Cryptococcus neoformans and Cryptococcus gattii. J Med Mycol. 2009;47:561-70. http://dx.doi.org/10.1080/ 13693780902953886

4. Byrnes EJ, Li W, Lewit Y, Ma H, Voelz K, Ren P, et al. Emergence and pathogenicity of highly virulent Cryptococcus gattii genotypes in the Northwest United States. PLoS Pathog. 2010;6:e1000850. http://dx.doi.org/10.1371/journal.ppat.1000850

5. Engelthaler DM, Hicks ND, Gillece JD, Roe CC, Schupp JM, Driebe EM, et al. Cryptococcus gattii in North America Pacific Northwest: whole-population genome analysis provides insights into the species evolution and dispersal. mBiol. 2014; 5:e01464 14. http://dx.doi.org/10.1128/mBio.01464-14

6. Marchinton R1, Hirth DH. Chapter 6: Behavior. In: Halls LK, editor. White-tailed deer: ecology and management. Harrisburg (PA): Stackpole Books; 1984. p. 129-68.

7. Duncan C, Schwantje H, Stephen C, Campbell J, Bartlett K. Cryptococcus gattii in wildlife of Vancouver Island, British Columbia, Canada. J Wildl Dis. 2006;42:175-8. http://dx.doi.org/ 10.7589/0090-3558-42.1.175

8. Kunadharaju R, Choe U, Harris JR, Lockhart SR, Greene JN. Cryptococcus gattii, Florida, USA, 2011. Emerg Infect Dis. 2013;19:519-21. http://dx.doi.org/10.3201/eid1903.121399

9. Lockhart SR, Iqbal N, Harris JR, Grossman NT, DeBess E, Wohrle R, et al. Cryptococcus gattii in the United States: genotypic diversity of human and veterinary isolates. PLoS ONE. 2013;8:e74737 http://dx.doi.org/10.1371/journal.pone.0074737.

Address for correspondence: David P. Overy, Department of Pathology and Microbiology, Atlantic Veterinary College, University of Prince Edward Island, 550 University of Prince Edward Island, Charlottetown, PEI, Canada; email: dovery@upei.ca

\title{
Zika Virus in a Traveler Returning to China from Caracas, Venezuela, February 2016
}

\section{Jiandong Li, ${ }^{1}$ Ying Xiong, ${ }^{1}$ Wei Wu, ${ }^{1}$ Xiaoqing Liu, ${ }^{1}$ Jing Qu, Xiang Zhao, Shuo Zhang, Jianhua Li, Weihong Li, Yong Liao, Tian Gong, Lijing Wang, Yong Shi, Yanfeng Xiong, Daxin Ni, Qun Li, Mifang Liang, Guoliang Hu, Dexin Li}

Author affiliations: National Institute for Viral Disease Control and Prevention, Chinese Center for Disease Control and Prevention, Beijing, China (Jiandong Li, W. Wu, J. Qu, X. Zhao, S. Zhang, L. Wang, M. Liang, D. Li); Jiangxi Provincial Center for Disease Control and Prevention, Nanchang, China (Y. Xiong, X. Liu, T. Gong, Y. Shi, G. Hu); Ganzhou Municipal Center for Disease Control and Prevention, Ganzhou, China (Jianhua Li, Y. Liao, Y. Xiong); Office of Emergence Response, Chinese Center for Disease Control and Prevention, Beijing (D. Ni, Q. Li); Beijing Center for Disease Prevention and Control, Beijing (W. Li)

DOI: http://dx.doi.org/10.3201/eid2206.160273

To the Editor: Zika virus, a member of the Flaviviridae family, is primarily transmitted through Aedes spp. mosquitoes, and evidence of vertical, sexual, and blood

${ }^{1}$ These authors contributed equally to this article. 
transmission of Zika virus has been reported (1-3). The virus has spread rapidly across Latin America and the Caribbean since the end of 2014 and has been linked to an increase in neurologic disorders and neonatal malformations in these areas (4). Zika virus has the potential to spread internationally through the carriage of goods and travelers (5). Traveler volume between China and areas with autochthonous transmission of Zika virus is increasing; in 2015, China received $\approx 84,000$ travelers who had departed from international airports in Brazil (5). The Ae. aegypti mosquito, the competent vector for Zika virus, is found in areas of Hainan, Guangdong, and Yunnan provinces on the mainland of China, where the known distribution is limited to areas below $22^{\circ}$ latitude. However, Ae. albopictus mosquitoes are widely distributed, extending from the southern reaches to the northern and western parts of China, with north fringes from Shenyang in Liaoning Province, through Tianshui and Longnan in Gansu Province, to Motuo in Tibet (6). Surveillance of Zika virus infection among Chinese travelers has been enhanced since January 2016. We report the clinical and laboratory findings for a case Zika virus infection imported from Venezuela.

A previously healthy 34-year-old Chinese man was admitted to the Hospital of Ganxian on February 6, 2016. He had worked in Caracas, Venezuela, during January 1February 2 and had onset of fever $\left(38.0^{\circ} \mathrm{C}\right)$, headache, and

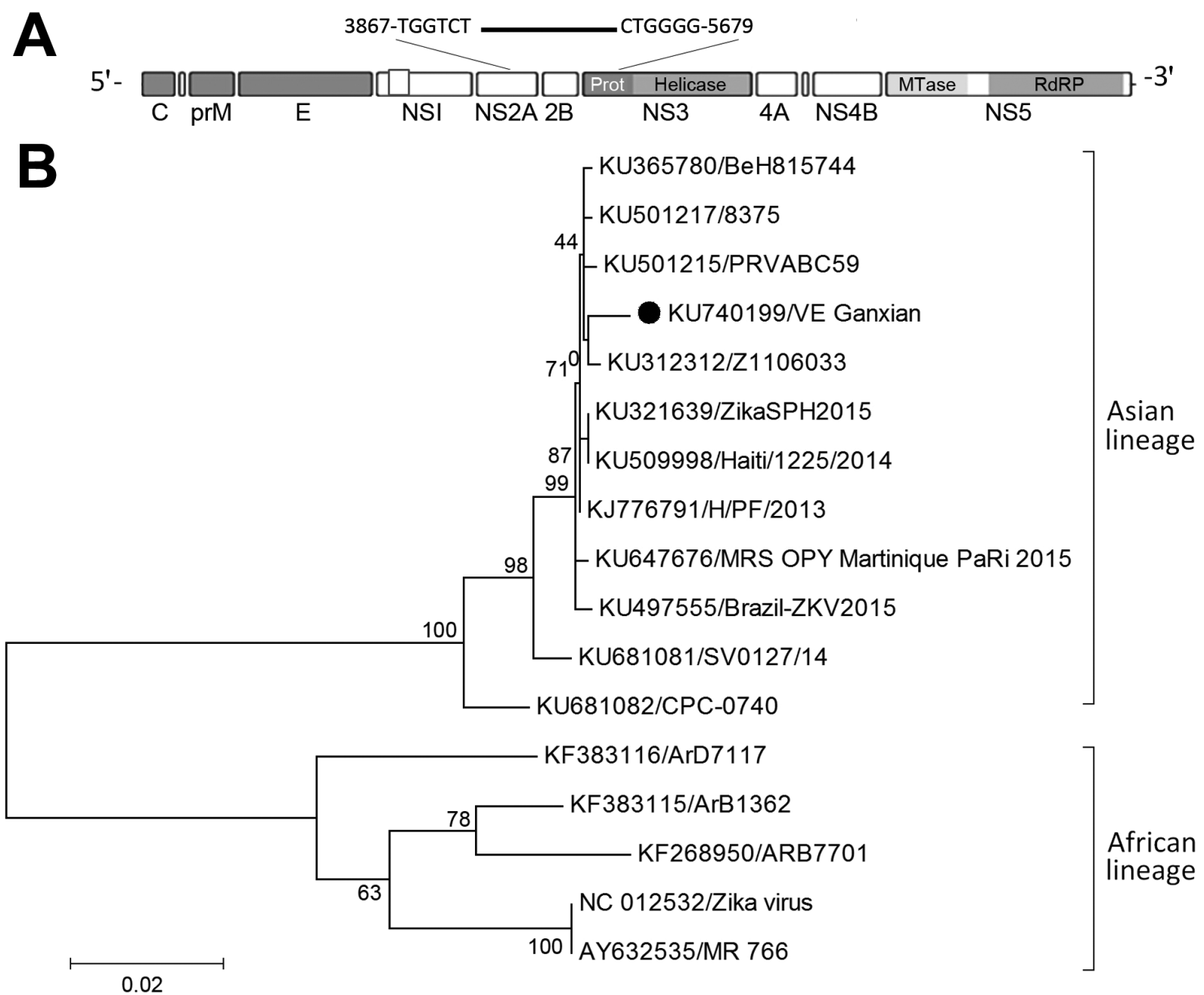

Figure. Phylogenetic analysis of partial sequences of Zika virus for an imported case of Zika virus infection in a traveler returning to China from Caracas, Venezuela, February 2016, compared with selected other strains from GenBank. A) Schematic diagram showing the contiguous sequence, obtained from de novo assembly and BLAST (http://blast.ncbi.nlm.nih.gov/Blast.cgi), targeted at the 3' terminus of nonstructural protein 2B and the $5^{\prime}$ terminus of nonstructural protein 3 genes (figure not drawn to scale). B) Maximumlikelihood phylogenetic tree inferred based on the Tamura-Nei model (8). The partial sequence of VE_Ganxian (black dot) obtained in this study was analyzed against 11 reference strains of Asian lineage and 5 reference strains of African lineage. All positions containing gaps and missing data were eliminated. Evolutionary analyses were conducted in MEGA version 7.0 (http://www.megasoftware. net). GenBank accession numbers are given. Scale bar indicates number of substitutions per site. C, capsid; E, envelope; MTase, methyltransferase; PrM, premembrane; RdRP, RNA-dependent RNA polymerase. 
dizziness on January 28 . He subsequently had rash, chills, retro-orbital pain, and mild diarrhea on February 2, the day on which he departed from Caracas and traveled to Jiangxi Province via Paris and Hong Kong, arriving in Shenzhen, China, on February 5. At the time of hospital admission, the patient had fever $\left(36.7^{\circ} \mathrm{C}\right)$, headache, conjunctivae, rash on his back and face, retro-orbital pain, and mild diarrhea. General clinical examination was unremarkable. Results of a complete blood cell count and liver function tests were within reference ranges.

Serum samples were collected at day 9 and day 10 after symptom onset, and urine samples were collected once a day from day 10 through day 14 . In the 2 serum samples, no dengue virus (DENV) or chikungunya virus (CHIKV) IgM or IgG were detected by a Panbio IgM and IgG capture ELISA for DENV (Panbio, Queensland, Australia) or by an indirect immunofluorescence assay slide test kit for CHIKV (EUROIMMUN AG, Lübeck, Germany). Serum and urine samples were negative for DENV nonstructural protein 1 (NS1) antigen on an NS1-ELISA test kit (Wantai Bio-Pharm, Beijing, China). To detect virus RNA in samples, in-house-designed probe and primers specific to DENV and CHIKV were used (7). The PCR for Zika virus was targeted to the NS1 gene. RNA was extracted from 140 $\mu \mathrm{L}$ of serum or urine by using the QIAamp Viral RNA Mini Kit (QIAGE, Hilden, Germany). Amplification reactions were performed by using the AgPath-ID One-Step RT-PCR Kit (Ambion, Carlsbad, CA, USA). A standard curve with serial dilutions of known concentrations of in vitro-transcribed RNA from a reference plasmid was used to estimate viral load in samples. Test results for DENV and CHIKV were negative. However, the serum sample collected at day 9 was positive for Zika virus RNA (viral load $1.4 \times 10^{4}$ copies $/ \mathrm{mL}$ ), and Zika virus RNA was detected from urine samples collected on days 10,11 , and 12 (viral loads $8.6 \times$ $10^{4}, 4.5 \times 10^{4}$, and $1.2 \times 10^{4}$ copies $/ \mathrm{mL}$, respectively).

Next-generation genomic sequencing of the Zika virus genome was conducted by using the MiSeq platform (Illumina, Hayward, CA, USA) on serum and urine samples. A 1,813-bp of partial genome sequences (strain VE_Ganxian, GenBank accession no. KU740199) was obtained from urine and was used for comparing with selected other strains from GenBank. Phylogenetic analysis showed that the virus was of Asian lineage (Figure). Pairwise genetic distance calculation indicated that the sequence was most closely related to other viruses reported from French Polynesia in 2013 (strain H/PF/2013), the Caribbean in 2014 (strain Haiti/1225/2014), and Latin America in 2015 (strain ZikaSPH2015), having a $99.4 \%$ similarity in sequence.

The clinical findings for the patient were similar to those previously reported among Zika virus-infected patients (9), although no arthralgia was apparent. Viral RNA remained detectable for 9 days after symptom onset in serum and for an additional 3 days in urine. We did not test this patient's semen and thus cannot comment on risk for onward sexual transmission; however, the patient was told about the risks for sexual transmission of Zika virus and was advised to adopt safer sexual practices or to abstain from sexual activity for at least 1 month after recovery. In February, the mosquito density is low in Jiangxi Province (10), suggesting that this imported case is unlikely to cause mosquitoborne transmission. However, with the onset of summer and increased density of Aedes mosquitos, the risk for onward transmission of travel-associated Zika virus should not be overlooked.

\section{Acknowledgments}

We thank the clinical workers from Ganxian Hospital for collecting the samples, and we thank all related laboratory and administrative personnel at the Chinese Center for Disease Control and Prevention and Jiangxi Province Center for Disease Control and Prevention.

This study was funded through the National Key Project for Infectious Disease (grant no. 2016ZX10004101).

\section{References}

1. Besnard M, Lastere S, Teissier A, Cao-Lormeau V, Musso D. Evidence of perinatal transmission of Zika virus, French Polynesia, December 2013 and February 2014. Euro Surveill. 2014;19:20751. http://dx.doi.org/10.2807/1560-7917.ES2014.19.13.20751

2. Musso D, Roche C, Robin E, Nhan T, Teissier A, Cao-Lormeau VM. Potential sexual transmission of Zika virus. Emerg Infect Dis. 2015;21:359-61. http://dx.doi.org/10.3201/eid2102.141363

3. Ioos S, Mallet HP, Leparc Goffart I, Gauthier V, Cardoso T, Herida M. Current Zika virus epidemiology and recent epidemics. Med Mal Infect. 2014;44:302-7. http://dx.doi.org/10.1016/ j.medmal.2014.04.008

4. Pan American Health Organization, World Health Organization. Epidemiological update: neurological syndrome, congenital anomalies, and Zika virus infection (17 January 2016) [cited 2016 Mar 7]. http://www.paho.org/hq/index.php?option=com docman\&task=doc_view\&Itemid=270\&gid=32879\&lang=en

5. Bogoch II, Brady OJ, Kraemer MU, German M, Creatore MI, Kulkarni MA, et al. Anticipating the international spread of Zika virus from Brazil. Lancet. 2016;387:335-6. http://dx.doi.org/ 10.1016/S0140-6736(16)00080-5

6. Xu RM. Geographic distribution of Aedes aegypti and Aedes albopictus. In: Lu, ML, ed. Vector of dengue fever and its prevention and control in mainland China. Gui Zhou (China): Gui Zhou People's Press; 1990. p. 51-55.

7. Pang Z, Li A, Li J, Qu J, He C, Zhang S, et al. Comprehensive multiplex one-step real-time TaqMan qRT-PCR assays for detection and quantification of hemorrhagic fever viruses. PLoS One. 2014;9:e95635. http://dx.doi.org/10.1371/ journal.pone.0095635

8. Tamura K, Nei M. Estimation of the number of nucleotide substitutions in the control region of mitochondrial DNA in humans and chimpanzees. Mol Biol Evol. 1993;10:512-26.

9. Duffy MR, Chen TH, Hancock WT, Powers AM, Kool JL, Lanciotti RS, et al. Zika virus outbreak on Yap Island, Federated States of Micronesia. N Engl J Med. 2009;360:2536-43. http://dx.doi.org/10.1056/NEJMoa0805715 
10. Lu L, Lin H, Tian L, Yang W, Sun J, Liu Q. Time series analysis of dengue fever and weather in Guangzhou, China. BMC Public Health. 2009;9:395. http://dx.doi.org/10.1186/1471-2458-9-395

Address for correspondence: Dexin Li, National Institute for Viral Disease Control and Prevention, Chinese Center for Disease Control and Prevention, Changbai Rd 155, Changping District, Beijing 102206, China; email: lidx@chinacdc.cn; or Guoliang Hu, Jiangxi Province Center for Disease Control and Prevention, Beijingdong Rd 555, Nanchang 330029, China; email: jxcdchg1@163.com

\section{Pericarditis Caused by Hyperinvasive Strain of Neisseria meningitidis, Sardinia, Italy, 2015}

\section{Cecilia Fazio, Paolo Castiglia, Andrea Piana, Arianna Neri, Maria S. Mura, Giorgia Caruana, Paola Vacca, Anna Anselmo, Andrea Ciammaruconi, Antonella Fortunato, Anna M. Palozzi, Silvia Fillo, Florigio Lista, Paola Stefanelli}

Author affiliations: Istituto Superiore di Sanità, Rome, Italy (C. Fazio, A. Neri, P. Vacca, P. Stefanelli); Università di Sassari, Sassari, Italy (P. Castiglia, A. Piana, M.S. Mura, G. Caruana); Centro Studi e Ricerche di Sanità e Veterinaria dell'Esercito, Rome (A. Anselmo, A. Ciammaruconi, A. Fortunato, A.M. Palozzi, S. Fillo, F. Lista)

\section{DOI: http://dx.doi.org/10.3201/eid2206.160160}

To the Editor: Invasive meningococcal disease is usually defined by the occurrence of meningitis or septicemia. Pericarditis might occur during the course of invasive infection. This clinical picture, defined as disseminated meningococcal disease with pericarditis (1) or secondary meningococcal pericarditis, was reported in 1918 (2). In 1939, primary or isolated meningococcal pericarditis $(1,3)$ was described. In this form of pericarditis, pericardial or blood cultures are positive for Neisseria meningitidis but there is no meningeal involvement or clinical meningococcemia (4).

Since its description, several cases of primary meningococcal pericarditis have been reported (5). Although its pathogenesis remains largely undefined, it has been hypothesized that the onset of primary pericarditis occurs after a transient bacteremia or as a consequence of involvement of the lower respiratory tract (4). Blaser et al. reported that serogroup $\mathrm{C}$ meningococci are usually associated with this disease, especially in adults. However, serogroups B,
$\mathrm{W}$, and $\mathrm{Y}$ have also been identified (4). We report a casepatient with primary meningococcal pericarditis caused by a serogroup $\mathrm{C}$ strain of $N$. meningitidis.

The patient was a 32-year-old man who lived in Sardinia, Italy. He had no predisposing factors, such as immunodeficiency or other chronic disorders. Disease onset occurred on August 29, 2015. Clinical manifestations were fever (temperature $38^{\circ} \mathrm{C}$ ), hypotension, epigastralgia, arthralgia, asthenia, chest pain, and reduced vesicular murmur. The left ventricle was widely hypokinetic, and a light ST increase was observed. A blood culture was positive for N. meningitidis.

The patient was given piperacillin/tazobactam $(4.5 \mathrm{~g}$ $3 \times / \mathrm{d})$ and metronidazole $(500 \mathrm{mg} 3 \times / \mathrm{d})$ for 4 days. After 4 days, treatment with ceftriaxone $(2 \mathrm{~g} 2 \times / \mathrm{d})$ for 4 days was started. Because of persistent fever $\left(38.8^{\circ} \mathrm{C}\right)$, levofloxacin (500 mg $2 \times / d$ ) for 23 days was also started on day 7 . On day 10 , ceftriaxone was replaced with piperacillin/tazobac$\operatorname{tam}(4.5 \mathrm{~g} 4 \times / \mathrm{d})$ for 21 days. A major bilateral pleural effusion was detected on the left side. On day 11, the fever had resolved. The outcome was favorable for this patient.

Drug resistance of the strain was determined by using the MIC Test Strip Method (Liofilchem, Abruzzi, Italy). Breakpoints used were those recommended by the European Committee on Antimicrobial Susceptibility Testing version 5.0 (http://www.eucast.org/). The strain was susceptible to cefotaxime, ceftriaxone, ciprofloxacin, penicillin $\mathrm{G}$, and rifampin. Serogroup was determined by using slide agglutination with commercial antisera (Remel Europe, Ltd., Dartford, UK) and confirmed by PCR ( 6 ).

Whole-genome sequencing was conducted to obtain molecular data and enable comparison with other meningococci of the same serogroup that were isolated in Italy. Multilocus sequence typing (MLST) and typing of porA and fetA genes and Bexsero (meningococcal group B vaccine) antigen genes (http://www.fda.gov/Biologics BloodVaccines/Vaccines/ApprovedProducts/ucm431374. $\mathrm{htm}$ ) were conducted as described (http://neisseria.org/). Whole-genome sequence was analyzed by using the BIGSdb Genome Comparator Tool (http://pubmlst.org/ neisseria/). Genomes of meningococci belonging to the same finetype were compared by using the core genome MLST (cgMLST) approach.

The $N$. meningitidis strain of serogroup C was susceptible to all antimicrobial drugs tested. Although serogroup $\mathrm{C}$ was associated with 53 (41\%) of 132 invasive meningococcal disease cases in Italy in 2015 (http://www.iss.it/ binary/mabi/cont/Report_MBI_20151223_v4.pdf), this serogroup has not been detected in Sardinia since 2010.

Molecular analyses showed that the strain belonged to the hypervirulent clonal complex (cc) 11, sequence type (ST) 11. The complete finetype was C:5-1,10-8:F3-6:ST11(cc11). This finetype has been reported in the United 